\title{
O imposto sobre produtos industrializados e o princípio da seletividade ${ }^{1}$
}

\author{
Reginaldo Lourenço Pierrotti Júnior ${ }^{2}$ \\ Luciane Wambier ${ }^{3}$
}

\section{Resumo}

\begin{abstract}
A grande concentração de pessoas em áreas metropolitanas, a crise no mercado de trabalho e o desemprego, demonstram a necessidade de formas adequadas de arrecadação de verbas pelo Estado. Hodiernamente, a maior parte da arrecadação pelos entes federativos se dá através da tributação. Entretanto, a tributação pode servir não só para a causa imediata de arrecadar verbas, como para formas de auxílio às políticas públicas visadas pelo Estado. No que tange ao imposto sobre produtos industrializados, de suma importância é o estudo do princípio da seletividade, visto que este, por possuir natureza de fiscalidade e extrafiscalidade, não só funciona como arrecadador de verbas aos cofres públicos, mas pode atuar em programas de governo e na economia, pondendo influir como grande incentivador do desenvolvimento do país.
\end{abstract}

Palavras-Chave: Tributação; Produtos industrializados; Princípio da seletividade; Fiscalidade; Extrafiscalidade.

\section{Introdução}

Sabe-se que atualmente a maior parte da arrecadação de verbas do Estado é através da tributação. O Estado Brasileiro possui carga tributária equivalente a dos países europeus.

Diante da extrema importância e necessidade da tributação, necessário se faz uma análise pormenorizada de cada exação, a fim de analisá-la desde a ocorrência do fato jurídico tributário até a formação da relação jurídica tributária.

A realidade atual, com grande concentração de pessoas em áreas metropolitanas, crise no mercado de trabalho, desemprego, demonstra a necessidade de um sistema tributário apropriado, que não piore ainda mais a situação da população mais carente.

\footnotetext{
Trabalho apresentado como requisito parcial de conclusão da disciplina de Direito Tributário, para conclusão do curso de Graduação em Direito da Universidade Estadual de Londrina.

2 Graduando em Direito pela Universidade Estadual de Londrina.

3 Graduanda em Direito pela Universidade Estadual de Londrina.
} 
Com efeito, o emprego adequado da tributação pode trazer ao Estado enormes benefícios, tais como reduzir as desigualdades sociais, implementar políticas públicas, incentivar o crescimento de determinado ramo da economia.

Nesse passo, percebe-se que o IPI (imposto sobre produtos industrializados) é um dos grandes responsáveis pela arrecadação tributária da União, de forma que imperioso se faz um pormenorizado de suas peculiaridades.

Nesse trabalho, estuda-se a regra-matriz de incidência do IPI, adotada pelo professor Paulo de Barros Carvalho, a fim de compreender melhor o citado imposto, para posteriormente, analisar sua efetiva aplicação.

O princípio da seletividade é um dos temas de maior importância no estudo do IPI, pois é através de seu aprimoramento que se dará o uso adequado do imposto em comento.

\section{A regra-matriz de incidência do IPI}

Para a melhor compreensão do tema imperioso se faz entender a aplicação da regra-matriz de incidência, pois que esta tem a finalidade de identificar a natureza jurídica o sentido e o alcance do imposto ora em análise.

A regra-matriz de incidência engloba tanto a hipótese que trará a previsão de um fato, quanto a conseqüencia que prescreverá a relação jurídica que se vai instaurar, onde e quando acontecer o fato cogitado no suposto (CARVALHO, 2005, p. 242).

Nesse passo, pode-se dizer que a regra-matriz de incidência se divide em: hipótese tributária, que se subdivide em critério material, criterio temporal, critério espacial; e relação jurídica tributária, que se subdivide em critério pessoal e critério quantitativo.

Pela análise do art. 153, IV da Constituição Federal de 1988, pode-se identificar os critérios que autorizam a formação da regra-matriz de incidência do IPI, visto que a Lei das Leis é quem estabelece e distribui as competências de cada ente federativo, de forma inequivoca, ditando a forma de atuação do legislador infra-constitucional.

\subsection{Hipótese tributária - o antecedente da norma}

Como bem explica o professor Paulo de Barros Carvalho, citando Lourival Vilanova, “a hipótese, como proposição descritiva de situação objetiva real é construída pela vontade 
do legislador, que recolhe os dados de fato da realidade, que deseja disciplinar (realidade social), qualificando-os, normativamente, comos fatos jurídicos" (VILANOVA apud CARVALHO, 2005, p. 255-256).

Desse modo, podemos verificar que o legislador seleciona as propriedades que julga importantes para caracterizar, o fato que dará ensejo ao surgimento da relação jurídica do tributo. Tais propriedades são conhecidas como: critério material, critério espacial e critério temporal.

\subsubsection{Critério material}

Critério material refere-se a um comportamento, tanto de possas físicas quanto jurídicas, condicionado por circunstâncias de espaço e tempo.

A hipótese de incidência do IPI são as operações com produtos industrializados, conforme se extrai do art. 153, IV, da CF/88, in verbis:

Art. 153. Compete à União instituir impostos sobre:

[...] IV- produtos industrializados; [...]

A definição de industrialização é de suma importância para a identificação do critério material. Nesse sentido, alguns autores entendem que a atividade de industrialização é aquela em que ocorre tranformação da matéria prima para se obter um produto novo.

Com efeito, produto industrializado é aquele que sofre alteração em sua natureza, visando a obtenção de uma nova utlilidade ou aprimoramento para o consumo e necessidades humanas, quando submetido a uma operação física, química, mecânica ou técnica.

Nesse rumo, pode-se excluir desse conceito o produto pecuário, agrícola, pesqueiro e demais produtos entendidos como extrativos. Da mesma forma, os objetos de arte e artesanato não podem ser considerados produtos industrializados.

O Código Tributário Nacional também trata do IPI, em seu art. 46, vejamos:

Art. 46. O imposto, de competência da União, sobre produtos industrializados tem como fato gerador:

I - o seu desembaraço aduaneiro, quando de procedência estrangeira; 
II - a sua saída dos estabelecimentos a que se refere o parágrafo único do artigo 51; III - a sua arrematação, quando apreendido ou abandonado e levado a leilão.

Portanto, deve-se concluir, a partir da leitura do art. 153, IV da CF/88, conjugado com o art. 46 do CTN, a despeito da discussão acerca da constitucionalidade desse dispositivo, que o critério material do IPI é composto: pelo verbo industrializar, seguido do complemento produtos; pelo verbo desembaração (importar), seguido do complemento produtos industrializados; por fim, do verbo arrematar, seguido do complemento produtos industrializados apreendidos ou abandonados.

\subsubsection{Critério espacial}

Conforme já mencionado, o critério espacial atua como uma das condicionantes do critério material. Assim, "há regras jurídicas que trazem expressos os locais em que o fato deve ocorrer, a fim de que irradie os efeitos que Ihe são característicos. Outras, porém, nada mencionam, carregando implícitos os indícios que nos permitem saber onde nasceu o laço obrigacional" (CARVALHO, 2005, p. 260).

No que toca ao IPI, as regras deixam implícitos os indícios que identificam o local do nascimento do laço obrigacional. Destarte, pode-se dizer que o fator condicionante espaço, leia-se critério espacial, traz pequena influência na elaboração do antecedente da norma, ou seja, qualquer lugar em que o fato ocorra, desde que dentro do campo de eficácia da norma, têm-se por realizados todos seus legítimos efeitos.

Diante disso, conclui-se que o critério espacial do IPI, corresponde a todo território nacional, ou seja, em qualquer lugar da nação onde se realizar o critério material, pois que é esse o campo de abrangência da norma instituidora dessa exação.

Contudo, algumas peculiaridades desse imposto devem ser apontadas, de tal sorte que na importação de produtos industrilizados, considera-se como critério espacial o local onde ocorrre o desembaraço aduaneiro, ou seja, a repartição aduaneira, alfândega, aduana ou porto seco. Também em caso de arrematação o critério espacial é o local de realização do leilão. 


\subsubsection{Critério temporal}

O critério temporal da regra-matriz de incidência é o condicionante do critério material que determina o momento em que se instala o vínculo obrigacional entre os sujeitos da relação.

No caso do tributo em estudo, o critério temporal, em regra, se dá no momento da saída dos produtos dos estabelecimentos industriais. Entretanto, nos casos de mercadoria importada, esse se dá no momento do desembaraço aduaneiro. Por fim, nos casos de produtos apreendidos ou abandonados, ocorrerá no momento da arrematação em leilão.

\subsection{Relação jurídica tributária - conseqüente da norma}

Das lições de Paulo de Barros Carvalho (2005, p. 286 e segs.), extrai-se que o conseqüente da norma é a peça do juízo hipotético que prevê a relação jurídica, instalada automaticamente assim que se concretiza o fato. Nessa fase, há prescrição de direitos e obrigações para as pessoas físicas ou jurídicas envolvidas, estibulando-se a regulação da conduta.

De toda hipótese tributária decorre uma relação jurídica tributária, que é composta por dois critérios: pessoal e quantitativo.

\subsubsection{Critério pessoal}

Critério pessoal é o conjunto de elementos, identificados no prescritor da norma, e que nos mostra quem são os sujeitos da relação jurídicas: sujeito ativo ou sujeito passivo.

O sujeito ativo é o credor ou pretensor, ou seja, aquele a quem a obrigação deve ser paga, vale dizer, toda pessoa que tem o poder de exigir o cumprimento de determinado dever. Na relação jurídica tributária, é o ente federativo que tem o poder de tributar, ou seja, aquele a quem a Constituição distribuiu a competência para instituição do tributo, que no caso do IPI é a União.

O sujeito passivo, por sua vez, é o devedor da obrigação tributária, ou seja, aquele de quem se exige o cumprimento de uma prestação, identificado como contribuinte. No caso do IPI, o art. 51 do CTN define expressamente quem é o contribuinte, in verbis: 
Art. 51. Contribuinte do imposto é:

I - o importador ou quem a lei a ele equiparar;

II - o industrial ou quem a lei a ele equiparar;

III - o comerciante de produtos sujeitos ao imposto, que os forneça aos contribuintes definidos no inciso anterior;

IV - o arrematante de produtos apreendidos ou abandonados, levados a leilão.

Parágrafo único. Para os efeitos deste imposto, considera-se contribuinte autônomo qualquer estabelecimento de importador, industrial, comerciante ou arrematante.

\subsubsection{Critério quantitativo}

O critério quantitativo tem por finalidade identificar o objeto prestacional, prescrevendo o valor que o sujeito passivo deve pagar ou que o sujeito ativo pode exigir. É composto por base de cálculo e alíquota.

Ricardo Malachias Ciconelo, citando Aires Barreto, preleciona que a base de cálculo "é a definção legal da unidade de medida constitutiva do padrão de referência a ser observado na quantificação financeira dos fatos tributários" (BARRETO apud CICONELO, 2003, p. 364).

A base de cálculo é um critério abstrato que mede os fatos tributários e que, conjugado à alíquota, determina o montante da dívida tributária.

No Código Tributário Nacional estão previstas as seguintes bases de cálculo para o IPI:

a) Produto de Procedência Estrangeira: O preço normal acrescido do imposto sobre importação, das taxas exigidas para entrada do produto do país e dos encargos cambiais efetivamente pagos pelo importador ou dele exigíveis.

b) Industrial ou Comerciante: O valor da operação de que decorrera a saída da mercadoria ou, na sua falta, o preço corrente da mercadoria ou seu similar no mercado atacadista.

c) Produtos Apreendidos ou Abandonados: preço da arrematação em leilão.

Do valor dimensionado através da base de cálculo o Estado chama para si um quota fração ou parte denominada alíquota.

A alíquota é o complemento da base de cálculo, visto que é pela combinação de ambas que se apura o valor da prestação pecuniária que o sujeito passivo deve ao ativo, ou seja, é através delas que se sabe o valor do tributo. 
As alíquotas referentes ao IPI estão dispostas na Tabela de Incidência do IPI, que classifica as mercadorias por diferentes sessões, capítulos e subdivisões.

É no critério quantitativo que o princípio da seletividade atua com maior influência, visto que a alíquota é fixada com base na essencialidade do produto industrializado.

\section{Princípios}

Para principiar o estudo de qualquer ramo do direito, imperioso faz-se começar por um dos mais importantes temas presente na literatura jurídica, os "princípios".

Os princípios jurídicos assumem basilar importância para a coordenação do sistema jurídico de qualquer país, seja ele regulamentado pelo commom law ou pelo civil law, esse último adotado pelo Brasil.

Isso acontece porque os princípios se subdividem em princípios gerais e específicos, os quais podem ser concretos ou abstratos.

Em nosso tema específico, dois são os princípios de fundamental importância, quais sejam, o da não cumulatividade e o da seletividade, pois que o IPI não está sujeito aos princípios da legalidade e da anterioridade.

Nesse interregno, aborda-se apenas a aplicação do princípio da seletividade no IPI.

\section{Aplicação do princípio da seletividade}

Dispõe a Lei das Leis, art. 153, § 3ำ, I, que o IPI "será seletivo em função da essencialidade do produto." Em apertada síntese a CF/88 quer dizer que haverá a aplicação do princípio da seletividade no IPI, de forma que se onerará mais o produto supérfluo.

A CF/88 é sucinta porque, em regra, os impostos tem função meramente arrecadatória, ou seja, são utilizados como instrumento de arrecadação de verbas aos cofres públicos. Nessa função, é nítida a natureza fiscal do IPI.

Contudo, há casos em que os impostos possuem nítida natureza extrafiscal, como é o caso do IPI. A extrafiscalidade consiste na utilização da exação para fins regulatórios, pois pode servir de instrumento para implementação de políticas monetárias, econômicas, de comércio exterior, de incentivo à produção de determinados setores etc. Vale dizer, serve de instrumento para o controle e intervenção de setores da economia nacional. 
A seletividade do IPI poderá ser utilizada a fim de favorecer, por meio de incidências mais leves, a realização de operações havidas por necessárias, úteis ou convenientes à sociedade e dificultar, por meio de incidências mais pesadas, a prática de atividades que não se mostrem de acordo com o interesse coletivo.

Diante disso, resta claro a íntima relação entre seletividade e a extrafiscalidade.

\subsection{A seletividade e a fiscalidade}

A incidência do IPI, em atendimento a sua natureza fiscal, deve estar em consonância com diversos princípios constitucionais, principalmente com o da capacidade contributiva. Desse modo, como não é possível identificar, entre os consumidores, quais são aqueles que possuem maior capacidade contributiva, ganha importância o princípio da seletividade que, através da progressão de alíquotas, busca onerar mais os produtos entendidos como supérfluos.

André de Souza Dantas Elali, citando Ricardo Lobo Torres, leciona no sentido de que a seletividade se dá em função da essencialidade do produto e é o único critério para a incidência do IPI. Para ele, significa dizer que o tributo recai sobre os bens na razão inversa de sua necessidade para o consumo popular e na razão direta de sua superfluidade (TORRES apud ELALI, 2005, p. 77).

Desse modo, pode-se concluir, resumidamente, que a seletividade, diante da natureza fiscal do IPI, atua ditando maior tributação aos produtos considerados supérfluos, do que aos produtos essenciais ao consumo. Isto porque presume-se que os produtos supérfluos são consumidos por pessoas de maior capacidade contributiva, enquanto os produtos essenciais são de necessidade de todos.

A aplicação do princípio da seletividade é o que justifica a maior oneração de produtos cosméticos, comparados com a oneração de produtos de limpeza.

\subsection{A seletividade e a extrafiscalidade}

Conforme ressaltado, o tributo, quando adequadamente utilizado, se distancia de sua função meramente arrecadatória e mostra-se apto a estimular consecução de metas para as quais se volta a ordem econômica (BOTELLO, 2002, p. 58). 
Nesse cenário, a extrafiscalidade do imposto sobre produtos industrializados ganha extrema importância, na medida em que funciona como instrumento hábil a estimular a produção de determinados produtos, bem como desestimular o consumo de outros.

Como exemplo da utilização do IPI como forma de estímulo da economia, impende citar a redução das alíquotas dos automóveis, concedida pelo Chefe do Executivo Federal, no ano passado, quando aquele setor passava por sérias crises produtivas.

Nesse passo, percebe-se que a Constituição faculta, como exceção e atendendo as limitações impostas na legislação, ao Poder Executivo Federal o poder de alterar as alíquotas do IPI.

\section{Conclusão}

No decorrer do trabalho, procura-se enfatizar a importância do estudo do IPI, partindo da análise da regra-matriz de incidência e todos os seus critério, bem como esclarecer acerca da grande necessidade de se usar a tributação de modo adequado, a fim de evitar o crescimento da desigualdade social e também como meio de controle e incentivo da economia. Diante disso, pode-se extrair as seguintes conclusões:

a) A regra-matriz de incidência é de suma importância na compreensão e estudo da tributação, mormente porque permite identificar todos os critérios formadores da norma jurídica individual e concreta;

b) O critério material do IPI é identificado pelo verbo industrializar e pelo complemento produtos, embora também possa incidir IPI na importação de produtos industrializados;

c) O critério espacial do IPI se manifesta implicitamente e, como imposto federal, abrange toda a área de eficácia da norma, ou seja, todo o território nacional;

d) O critério temporal é momento em que o produto sai da indústria, ou do desembaraço aduaneiro ou da venda em leilão;

e) No que toca ao conseqüente da norma, a relação jurídica tributária é identificada pelo critério pessoal, sendo a União o sujeito ativo, e o produtor, importador, arrematante de produtos industrializados, sujeito passivo;

f) O critério quantitativo é composto pela base de cálculo e pela alíquota, que juntas delimitaram o valor a ser pago pelo sujeito passivo ao sujeito ativo; 
g) O IPI possui natureza jurídica fiscal, pois funciona como arrecadador de verbas aos cofres públicos, e extrafiscal, porque também pode atuar em programas de governo e na economia.

h) Ao IPI, atendendo tanto em sua natureza fiscal, quanto na sua natureza extrafiscal é aplicado o princípio da seletividade;

i) O princípio da seletividade significa onerar mais o produto mais supérfluo e menos o produto essencial;

j) A seletividade pode ser aplicada à extrafiscalidade no sentido de onerar menos determinado produto que interessa aumentar a produção.

\section{Referências}

BOTTELLO, Eduardo Domingos. Fundamentos do IPI (Impostos sobre produtos industrializados). São Paulo: Revista dos Tribunais, 2002.

CARRAZZA, Roque Antonio. Curso de Direito Constitucional Tributário. 21. ed. rev. ampl. e atual. até a Emenda Constitucional n 48/2005. São Paulo: Malheiros, 2005.

CARVALHO, Paulo de Barros. Curso de Direito Tributário. 17. ed. São Paulo: Saraiva, 2005.

CICONELO, Ricardo Malachias. IPI - Aspectos Jurídicos Relevantes. 1. ed. São Paulo: Quartier Latin, 2003.

ELALI, André de Souza Dantas. IPI: aspectos práticos e teóricos. 1. ed. Curitiba: Juruá, 2005.

PEIXOTO, Marcelo Magalhães (Coord.) IPI - Aspectos Jurídicos Relevantes. São Paulo: Quartier Latin, 2003.

ROSA JR., Luiz Emygdio F. Da. Manual de Direito Financeiro \& Direito Tributário. 15. ed. Rio de Janeiro: Renovar, 2001.

TORRES, Ricardo Lobo. Curso de Direito Financeiro e Tributário. 9. ed. Rio de Janeiro: Renovar, 2002. 